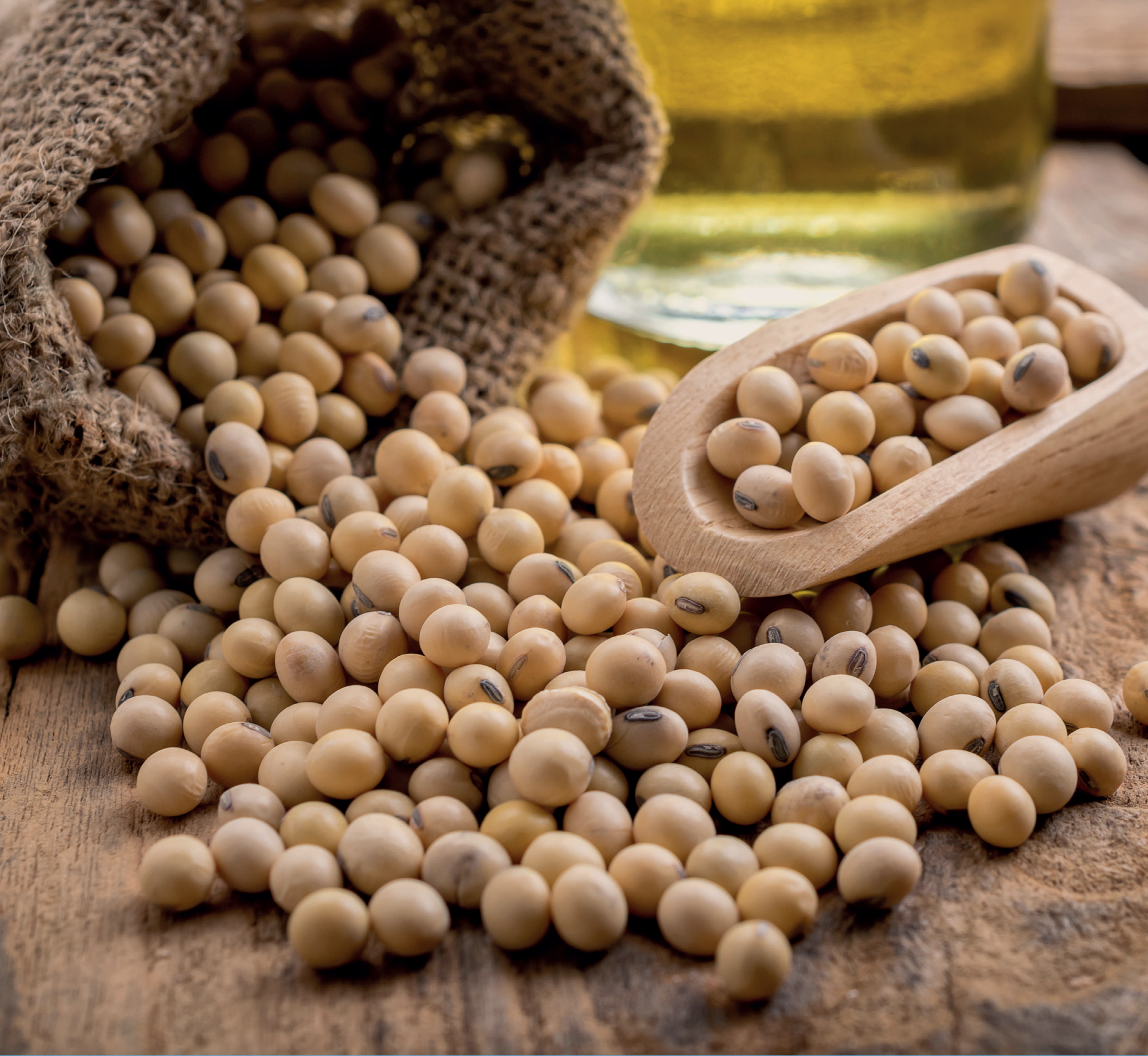

\title{
Proficiency test for diquat and paraquat in soybean meal
}





\section{Proficiency test for diquat and paraquat in soybean meal}

D.P.K.H. Pereboom, J. de Jong, J.G.J. Mol and W.C.M. de Nijs

This research has been carried out by Wageningen Food Safety Research, institute within the legal entity Wageningen Research Foundation funded by the Dutch Ministry of Agriculture, Nature and Food Quality, WOT programme Food Safety, theme Animal Feed.

Wageningen, July 2020

WFSR report 2020.013 
D.P.K.H. Pereboom, J de Jong, J.G.J. Mol and W.C.M. de Nijs, 2020. Proficiency test for diquat and paraquat in soybean meal. Wageningen, Wageningen Food Safety Research, WFSR report 2020.013. 30 pp.; 0 fig.; 7 tab.; 10 ref.

Project number: 1227248801-WOT BPL

Project title: Borging private laboratoria (WOT-02-004-004)

Coordinator proficiency tests: D.P.K.H. Pereboom

Project leader: W.C.M. de Nijs

This report can be downloaded for free at https://doi.org/10.18174/526153 or at www.wur.eu/foodsafety-research (under WFSR publications).

(C) 2020 Wageningen Food Safety Research, institute within the legal entity Wageningen Research Foundation. Hereinafter referred to as WFSR.

The client is allowed to publish or distribute the full report to third parties. Without prior written permission from WFSR it is not allowed to:

a) publish parts of this report;

b) use this report or title of this report in conducting legal procedures, for advertising, acquisition or other commercial purposes;

c) use the name of WFSR other than as the author of this report.

P.O. Box 230, 6700 AE Wageningen, The Netherlands, T +31 (0)317 4802 56, E info.wfsr@wur.nl, www.wur.eu/food-safety-research. WFSR is part of Wageningen University \& Research.

This report from WFSR has been produced with the utmost care. However, WFSR does not accept liability for any claims based on the contents of this report.

WFSR report 2020.013

Distribution list:

- Eighteen participating laboratories 


\section{Contents}

$\begin{array}{ll}\text { Summary } & 5\end{array}$

$\begin{array}{ll}\text { Introduction } & 7\end{array}$

2

$\begin{array}{lr}\text { Material and methods } & 8\end{array}$

$\begin{array}{lll}2.1 & \text { Scope of the proficiency test } & 8\end{array}$

2.2 Material preparation $\quad 8$

2.3 Sample identification $\quad 8$

2.4 Homogeneity study $\quad 8$

2.5 Stability of the materials $\quad 9$

$\begin{array}{lll}2.6 & \text { Interpretation of the results } & 9\end{array}$

$3 \quad$ Organisational details $r$

$\begin{array}{lll}3.1 & \text { Participants } & 10\end{array}$

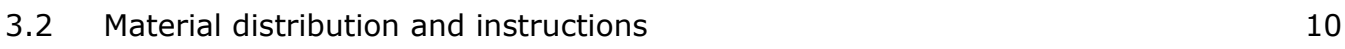

4.1 Calculation of the consensus value $\quad 11$

4.2 Calculation of the uncertainty of the consensus value 11

4.3 Calculation of the standard deviation for proficiency assessment $\left(\sigma_{P}\right) \quad 12$

$\begin{array}{ll}\text { 4.4 Performance characteristics with regard to the accuracy } & 12\end{array}$

$\begin{array}{llr}5 & \text { Methods and results } & 14\end{array}$

5.1 Participants $\quad 14$

5.2 Methods of analysis applied by participants $\quad 14$

5.3 Performance 14

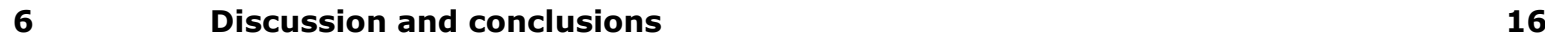

$\begin{array}{ll}\text { References } & 17\end{array}$

$\begin{array}{lll}\text { Annex } 1 & \text { Codification of the samples } & 18\end{array}$

Annex 2 Instruction letter $\quad 19$

$\begin{array}{lll}\text { Annex } 3 & \text { Statistical evaluation of homogeneity data } & 21\end{array}$

$\begin{array}{lll}\text { Annex } 4 & \text { Statistical evaluation of stability data } & 23\end{array}$

Annex 5 Overview of the applied methods 25

$\begin{array}{lll}\text { Annex } 6 & \text { Results material A and B } & 26\end{array}$

$\begin{array}{lll}\text { Annex } 7 & \text { Overview performance per laboratory } & 29\end{array}$ 



\section{Summary}

In October 2019, a proficiency test for diquat and paraquat (bipyridylium herbicides/desiccants) in soybean meal was organised by Wageningen Food Safety Research (WFSR), part of Wageningen University \& Research in accordance with ISO 17043. WFSR, is accredited for the organisation of proficiency tests in the field of contaminants, pesticides, mycotoxins, plant toxins and veterinary drugs in feed and feed ingredients according to ISO/IEC 17043 (R013). The primary goal of this proficiency test was to give participants the opportunity to evaluate and demonstrate their competence for the analysis of diquat and paraquat in soybean meal.

Two materials were prepared and dispatched on dry-ice to the participants. The consensus values of the two pesticides in each material are given in Table 1.

Table 1 Consensus values of the diquat and paraquat in the proficiency materials.

\begin{tabular}{lcc} 
& Material A & Material B \\
\hline Compound & Consensus value & Consensus value \\
diquat & $\mu \mathrm{gg} / \mathrm{kg}$ & 96.7 \\
\hline paraquat & 267 & 129 \\
\hline
\end{tabular}

Material $A$ and $B$ were prepared by spiking a solution of diquat and paraquat to soybean meal to the required target concentrations. The materials were mixed with water followed by extensive mixing, freeze-drying and milling of the samples. Each participant received one test sample of each material.

Homogeneity assessment showed that both materials were sufficiently homogeneous for proficiency testing. The stability test demonstrated no statistically significant loss of the polar pesticides.

Eighteen laboratories participated in this proficiency test. The proficiency of the participants was assessed through z-scores, calculated using the consensus value and a target relative standard deviation of $25 \%$.

The results of the proficiency test on polar pesticides in soybean meal are summarized in Table 2. A total of $72 \mathrm{z}$-scores could be calculated from the submitted results of which seven questionable z-scores and two unsatisfactory z-scores were reported. No false negative results were reported. Twelve participants achieved optimal performance for both materials by detecting both pesticides with the correct quantification, the absence of false negative results and reporting within the indicated deadline. Six participants reported questionable or unsatisfactory z-scores.

Table 2 Summarized performance of laboratories reporting results in the proficiency test on diquat and paraquat in materials $A$ and $B$.

\begin{tabular}{lcc} 
Compound & \# of the results & Satisfactory performance $(\%)$ \\
\hline diquat & Material A (soybean meal) & 94 \\
\hline paraquat & 18 & 94 \\
\hline & 18 & \\
\hline diquat & Material B (soybean meal) & 78 \\
\hline paraquat & 18 & 83
\end{tabular}


Based on the results of this test it can be concluded that the variation in results for diquat in material $A$ was higher than paraquat in material $A$ and diquat and paraquat in material $B$. The interlaboratory reproducibility $\left(\mathrm{RSD}_{R}\right)$ ranged from $21-36 \%$. The satisfactory results varied from 78 to $94 \%$. No clear explanation could be found for the higher $\mathrm{RSD}_{\mathrm{R}}$ for diquat $(36 \%)$ in material $A$ and the lower satisfactory results for diquat (78\%) and paraquat $(83 \%)$ in material $\mathrm{B}$. 


\section{Introduction}

Proficiency testing is conducted to provide participants with a powerful tool to evaluate and demonstrate the reliability of the data that are produced by the laboratory. Proficiency testing is an important requirement and demanded by ISO/IEC 17025:2017 [1].

The preparation of the materials, including the homogeneity and stability testing of the materials, and the evaluation of the quantitative results were carried out under accreditation according to ISO/IEC 17043:2010 [2] accreditation by the Dutch Accreditation Board (R013).

Diquat and paraquat are bipyridylium compounds that are used as herbicide or desiccant. Paraquat has been banned for use in the EU since 2007. Diquat was no longer approved in the EU from 2019 (max period of grace: 4 February 2020). Both compounds are however still used elsewhere. In the EU, maximum residue level(MRL) for diquat in soybeans is $0.3 \mathrm{mg} / \mathrm{kg}$ and for paraquat in soybeans is $0.02 \mathrm{mg} / \mathrm{kg}$ and has been set in (Regulation (EC) No 396/2005 [9] and amendments thereof. For the matrix soybean meal as such, no specific MRLs have been set and MRLs derived from soybeans after taking processing factors into account apply.

The aim of this proficiency test was to give participants the opportunity to evaluate or demonstrate their competence for the analysis of diquat and paraquat in soybean meal. 


\section{Material and methods}

\subsection{Scope of the proficiency test}

This proficiency test (PT) focused on the pesticides diquat and paraquat in the feed matrix soybean meal. The target concentrations for the pesticides in this PT are presented in Table 3. The soybean meal is a by-product released during the extraction of soybean oil.

\subsection{Material preparation}

For preparation of the two PT materials A and B, soybean meal was used. Levels were artificially increased by spiking with diquat and paraquat. For each material, two kilograms were first fortified by adding a solution of a pesticide mix in water, aiming at the levels as presented in Table 3 . The materials were mixed with approximately six litres of water, homogenized using an industrial mixer according to an in-house standard operating procedure [3]. The fortified slurries were freeze-dried, homogenized in a Stephan cutter, and stored in the freezer until use.

Table 3 Target concentrations of polar pesticides in the proficiency materials.

\begin{tabular}{lcc} 
& Material A & Material B \\
Compound & Target concentration $(\mu \mathrm{g} / \mathrm{kg})$ & Target concentration $(\mu \mathrm{g} / \mathrm{kg})$ \\
diquat & 300 & 100 \\
\hline paraquat & 50 & 150 \\
\hline
\end{tabular}

\subsection{Sample identification}

After homogenization, materials A and B were divided into sub-portions of approximately 50 grams in polypropylene, airtight closed containers of $125 \mathrm{ml}$. The containers were stored in the freezer until use.

The samples for the participants were randomly selected and coded using a web application designed for PTs (Annex 1). The code used was 2020/pesticides/soybean/000, in which the three digit number at the end of the code was automatically generated by the WFSR Laboratory Quality Services web application. One sample set was prepared for each laboratory consisting of one randomly selected sample of each material $A$ and $B$. The codes of the samples for each sample set are presented in Annex 1. For homogeneity and stability testing, randomly selected containers of material A and B were used.

\subsection{Homogeneity study}

To verify the homogeneity of the PT materials, ten containers of material A and B were analysed in duplicate for diquat and paraquat. The homogeneity of the materials was assessed according to The International Harmonized Protocol for Proficiency Testing of Analytical Laboratories [6] and ISO 13528:2015 [4]. For homogeneity a target standard deviation for proficiency assessment $\left(\sigma_{P}\right)$ of $25 \%$ was used as a fit-for-purpose standard deviation, in line with the target RSD used in proficiency tests on pesticides as organised by the pesticides EURLs[10]. With this procedure the between-sample standard deviation $\left(\mathrm{s}_{\mathrm{s}}\right)$ and the within-sample standard deviation $\left(\mathrm{s}_{\mathrm{w}}\right)$ were compared with the 
standard deviation for proficiency assessment. The method applied for homogeneity testing is considered suitable if $\mathrm{s}_{\mathrm{w}}<0.5^{*} \sigma_{\mathrm{p}}$ and a material is considered adequately homogeneous if $\mathrm{s}_{\mathrm{s}}<0.3^{*} \sigma_{\mathrm{p}}$. The results of the homogeneity study, the grand mean with the corresponding RSD are presented in Table 4 and the statistical evaluation of material A and material B are presented in Annex 3. Diquat and paraquat in both materials fulfilled the homogeneity-criterion.

Table 4 Concentration of pesticides in materials A and B obtained during homogeneity testing.

\begin{tabular}{|c|c|c|c|c|}
\hline \multirow[t]{3}{*}{ Material code } & \multicolumn{2}{|c|}{ Material A } & \multicolumn{2}{|c|}{ Material B } \\
\hline & Concentration & RSD & Concentration & RSD \\
\hline & $\mu \mathrm{g} / \mathbf{k g}$ & $\%$ & $\mu \mathrm{g} / \mathrm{kg}$ & $\%$ \\
\hline paraquat & 53.5 & 4.46 & 146 & 6.42 \\
\hline
\end{tabular}

\subsection{Stability of the materials}

The stability of the mycotoxins in the PT materials was assessed according to [5, 7]. On January $20^{\text {th }}$, 2020 , the day of distribution of the PT samples, six randomly selected containers of each material A and $\mathrm{B}$ were stored at $<-18^{\circ} \mathrm{C}$. Under these conditions it is assumed that diquat and paraquat are stable in the materials. Another six containers remained stored at $<4{ }^{\circ} \mathrm{C}$.

On April $13^{\text {th }}, 2020,87$ days after distribution of the samples, for each of the storage conditions $\left(<-18^{\circ} \mathrm{C},<4^{\circ} \mathrm{C}\right)$ six samples of materials $A$ and $B$ were analysed for both pesticides. For each set of test samples, the average of the results and the standard deviation were calculated.

It was determined whether a consequential instability of the analytes occurred [5, 7] in the materials stored at $<4^{\circ} \mathrm{C}$. A consequential instability is observed when the average value of an analyte in the samples stored at $<4{ }^{\circ} \mathrm{C}$ is more than $0.3 \sigma_{\mathrm{p}}$ below the average value of the analyte in the samples stored at $<-18^{\circ} \mathrm{C}$. If so, the instability has a significant influence on the calculated z-scores.

The results of the stability of materials $A$ and $B$ are presented in Annex 4. In none of the pesticide/storage condition combinations, a consequential difference was observed. Diquat and paraquat in the materials were therefore considered stable for the duration of the PT.

\subsection{Interpretation of the results}

A result was assigned as false negative result if a compound was ' $<$ [value]' or 'not detected' (nd), taking into account the reported scope of the participant, the consensus value and the reported LOQ for the compound by the participant. False negatives are indicated as 'FN'. False negatives are to be interpreted as unsatisfactory performance.

For example: the consensus value of compound $A$ is $70 \mu \mathrm{g} / \mathrm{kg}$ and the participant reported an $L O Q=$ $20 \mu \mathrm{g} / \mathrm{kg}$ for this compound. Taken into account the $25 \%$ target standard deviation in this test, the $2 z$ threshold would be at $35 \mu \mathrm{g} / \mathrm{kg}$ (70-(2*25\% of 70)). Since the LOQ of this participant is lower than the $-2 z$ value, this participant should be able to detect the presence. If the LOQ would have been $40 \mu \mathrm{g} / \mathrm{kg}$ no false negative result would be assigned.

Also, when no LOQ values were reported and the compound was reported as ' $<$ [value]' or (nd) a false negative result was assigned. 


\section{Organisational details}

\subsection{Participants}

Nineteen participants registered for the participation in the PT and 18 participants reported their results. All participants were situated in Europe. One participant was unable to report result due to lack of laboratory capacity. Each participant was free to use their method of choice reflecting their routine procedures. The participants were asked to report the results through an existing web application designed for proficiency tests organised by WFSR.

\subsection{Material distribution and instructions}

Each participant received a randomly assigned laboratory code, generated by the web application. The sets of samples with the corresponding number, were sent to the PT participants on the $20^{\text {th }}$ of January 2020. The sets of samples were packed in insulation boxes containing dry ice and were dispatched to the participants immediately by courier. The participants were asked to store the samples at $<4{ }^{\circ} \mathrm{C}$ and to analyse the samples according to their routine practice. As reported by the participants, all parcels were received within 24 hours after dispatch, except one parcel that took 48 hours to reach the laboratory. All samples were received in good order.

The samples were accompanied by a letter describing the requested analysis (Annex 2) and an acknowledgement of receipt form. In addition, by e-mail, each participant received instructions on how to use the web application to report the results. Results should be reported as $\mu \mathrm{g} / \mathrm{kg}$ product (no correction for moisture). Participants were asked to provide information on their analytical method (extraction solvent, clean-up procedure, internal standards used, detection technique, limit of detection, limit of quantification).

A single analysis result for both pesticides in each sample was requested. The deadline for submitting the quantitative results was the $2^{\text {nd }}$ of March 2020, allowing the participants six weeks for analysis of the test samples. All results, were submitted within the deadline. 


\section{Statistical evaluation}

The statistical evaluation was carried out according to the International Harmonized Protocol for the Proficiency Testing of Analytical Laboratories [6], elaborated by ISO, IUPAC and AOAC and ISO

13528:2015 [4] in combination with the insights published by the Analytical Methods Committee $[7,8]$ regarding robust statistics.

For the evaluation of the quantitative results, the consensus value, the uncertainty of the consensus value, the standard deviation for proficiency assessment and z-scores were calculated.

\subsection{Calculation of the consensus value}

The consensus value $(X)$ was determined using robust statistics $[4,7,8]$. The advantage of robust statistics is that all values are taken into account: outlying observations are retained, but given less weight. Furthermore, it is not expected to receive normally distributed data in a proficiency test. When using robust statistics, the data do not have to be normally distributed in contrast to conventional outlier elimination methods.

The robust mean of the reported results of all participants, calculated from an iterative process that starts at the median of the reported results using a cut-off value depending on the number of results, was used as the consensus value $[4,7]$.

\subsection{Calculation of the uncertainty of the consensus value}

The uncertainty of the consensus value is calculated to determine the influence of this uncertainty on the evaluation of the participants. A high uncertainty of the consensus value will lead to a high uncertainty of the calculated participants $z_{a}$-scores. If the uncertainty of the consensus value and thus the uncertainty of the $z_{a}$-score is high, the evaluation could indicate unsatisfactory method performance without any cause within the laboratory. In other words, illegitimate conclusions could be drawn regarding the performance of the participating participants from the calculated $z_{a}$-scores if the uncertainty of the consensus value is not taken into account.

The uncertainty of the consensus value (the robust mean) is calculated from the estimation of the standard deviation of the consensus value and the number of values used for the calculation of the consensus value [4]:

$\mathrm{u}=1.25 * \frac{\hat{\sigma}}{\sqrt{\mathrm{n}}}$

where:

$\mathrm{u}=$ Uncertainty of the consensus value;

$\mathrm{n}=$ Number of values used to calculate the consensus value;

$\hat{\sigma}=$ The estimate of the standard deviation of the consensus value resulting from robust statistics. 
According to ISO $13528: 2015$ [4] the uncertainty of the consensus value $(u)$ is negligible and therefore does not have to be included in the statistical evaluation if:

$u \leq 0.3 \sigma_{\mathrm{p}}$

where:

$\mathrm{u}=$ The uncertainty of the consensus value;

$\sigma_{\mathrm{P}}=$ Standard deviation for proficiency assessment (§3.3).

In case the uncertainty of the consensus value does not comply with this criterion, the uncertainty of the consensus value should be taken into account when evaluating the performance of the participants regarding the accuracy (§3.4). In case the uncertainty is $>0.7 \sigma_{\mathrm{p}}$ the calculated $z$-scores should not be used for evaluation of participants performance and are presented for information only.

\subsection{Calculation of the standard deviation for proficiency assessment $\left(\sigma_{P}\right)$}

A target standard deviation for proficiency assessment $\left(\sigma_{P}\right)$ of $25 \%$ was used as a fit-for-purpose standard deviation which is in line with the target RSD used in proficiency tests on mycotoxins as organised by the EURL.

$\sigma_{\mathrm{P}}=0.25 \mathrm{C}$

where:

$\sigma_{\mathrm{P}}=$ Expected standard deviation in proficiency tests for animal feed;

$c=$ Concentration of the analyte $(\mu \mathrm{g} / \mathrm{kg})$.

\subsection{Performance characteristics with regard to the accuracy}

For illustrating the performance of the participating participants with regard to the accuracy a $\mathrm{z}_{\mathrm{a}}$-score is calculated. For the evaluation of the performance of the participants, ISO 13528:2015 [4] is applied. According to these guidelines $\mathrm{z}_{\mathrm{a}}$-scores are classified as presented in Table 5.

Table 5 Classification of $z_{a}$-scores.

\begin{tabular}{cc}
\hline$\left|z_{a}\right| \leq 2$ & Satisfactory \\
\hline $2<\left|z_{a}\right|<3$ & Questionable \\
\hline$\left|z_{a}\right| \geq 3$ & Unsatisfactory
\end{tabular}

If the calculated uncertainty of the consensus value complies with the criterion mentioned in $\S 3.2$, the uncertainty is negligible. In this case the accuracy z-score is calculated from:

$\mathrm{z}_{\mathrm{a}}=\frac{\mathrm{X}-\mathrm{X}}{\sigma_{\mathrm{p}}}$

where:

$\mathrm{z}_{\mathrm{a}}=$ Accuracy $\mathrm{z}$-score;

$\bar{x}=$ The average result of the laboratory;

$\mathrm{X}=$ Consensus value;

$\sigma_{\mathrm{P}}=$ Standard deviation for proficiency assessment. 
However, if the uncertainty of the consensus value does not comply with the criterion mentioned in $\S 3.2$, it could influence the evaluation of the participants. Although, according to ISO 13528 in this case no z-scores can be calculated, we feel that evaluation of the participating participants is of main importance justifying the participating participants' effort. Therefore in this case, the uncertainty is taken into account by calculating the accuracy z-score [4]:

$z_{a}^{\prime}=\frac{x-X}{\sqrt{\sigma_{p}^{2}+u^{2}}}$

Equation II

where:

$\mathrm{z}_{\mathrm{a}}^{\prime}=$ Accuracy $z$-score taking into account the uncertainty of the consensus value;

$\bar{x}=$ The average result of the laboratory;

$\mathrm{X}=$ Consensus value;

$\sigma_{\mathrm{P}}=$ Standard deviation for proficiency assessment;

$\mathrm{u}=$ Uncertainty of the consensus value.

A consequential instability of the proficiency materials can influence the evaluation of the laboratory performance. Therefore, in that case the consequential instability is taken into account when calculating z-scores. Because instability only regards one side of the confidence interval (a decrease of the concentration) this correction only applies to the lower $2 \mathrm{~s}$ limit and results in an asymmetrical confidence interval.

In the case of a consequential instability the accuracy z-score for the participants that reported an amount below the consensus value is corrected for this instability by:

$z_{\mathrm{ai}}=\frac{\bar{X}-X}{\sqrt{\sigma_{\mathrm{p}}^{2}+\Delta^{2}}}$

Equation III

where:

$\mathrm{z}_{\overline{\mathrm{ai}}}=$ Accuracy $z$-score taking into account the instability of the consensus value;

$\bar{x}=$ The average result of the laboratory;

$\mathrm{X}=$ Consensus value;

$\sigma_{\mathrm{P}}=$ Standard deviation for proficiency assessment;

$\Delta=$ Difference between average concentration of compound stored at $<-18{ }^{\circ} \mathrm{C}$ and average concentration at $<4^{\circ} \mathrm{C}$.

In some cases the uncertainty of the consensus value does not comply with the criterion in $\S 3.2$ and a consequential instability is observed. In this case the $\mathrm{z}_{\mathrm{a}}{ }_{\mathrm{a}}$-score for the participants that reported an amount below the consensus value is corrected for this instability by:

$Z^{\prime}{ }_{a i}=\frac{X-X}{\sqrt{\sigma_{p}^{2}+\Delta^{2}+u^{2}}}$

Equation IV

where:

$\mathrm{z}^{\prime}{ }_{\mathrm{ai}}=$ Accuracy $\mathrm{z}$-score taking into account the uncertainty and instability of the consensus value;

$\bar{x}=$ The average result of the laboratory;

$\mathrm{X}=$ Consensus value;

$\sigma_{\mathrm{P}} \quad=$ Standard deviation for proficiency assessment;

$\Delta=$ Difference between average concentration of compound stored at $<-18{ }^{\circ} \mathrm{C}$ and average concentration at $<4{ }^{\circ} \mathrm{C}$;

$\mathrm{u}=$ Uncertainty of the consensus value. 


\section{$5 \quad$ Methods and results}

\subsection{Participants}

Nineteen participants registered for the PT and 18 participants submitted their results. Each participant was free to use their method of choice reflecting their routine procedures. The performance of individual participants is summarized in Annex 7.

\subsection{Methods of analysis applied by participants}

An overview of the information provided by the participants regarding the methods applied in this PT is presented in Annex 5. The information provided was not always complete. Four participants provided no information at all.

In general, diquat and paraquat were extracted under (strong) acidic conditions (water/methanol with $\mathrm{HCl}$ or formic acid). Four participants performed the extraction at higher temperature $\left(80^{\circ} \mathrm{C}\right)$. In most cases no clean-up was used, some laboratories used an SPE clean-up. In most cases, isotopic labelled diquat and paraquat were used as internal standards. The extracts were analysed by LC-MS/MS in all cases.

Ranges for the reported limits of detection (LODs) and limits of quantification (LOQs) for the pesticides are presented in Table 6. One participant reported an LOQ of $0.01 \mu \mathrm{g} / \mathrm{kg}$ which may have been an unit error. Four participants did not indicate the LODs and LOQs of the method used.

Table 6 Overview of reported $L O D$ and $L O Q$ reported by the participants.

\begin{tabular}{lcc} 
Compound & LOD $(\mu g / \mathrm{kg})$ & $\mathrm{LOQ}(\mu \mathrm{gg} / \mathrm{kg})$ \\
Diquat & $1.7-10$ & $5.6-20$ \\
\hline Paraquat & $2-19$ & $6.8-20$ \\
\hline
\end{tabular}

\subsection{Performance}

The quantitative performance was assessed through z-scores. The individual z-scores obtained by each participant, including their graphical representation, for pesticides in materials $A$ and $B$ are summarised in Annex 6. A summary of the performance of the participants in this PT is provided in Annex 7.

A summary of the statistical evaluation of the PT results is presented in Table 7. This table include all relevant parameters: the consensus value $(\mathrm{CV})$, the uncertainty of the assigned value $(\mathrm{u})$, the standard deviation for proficiency assessment $\left(\sigma_{p}\right)$ and the robust (relative) standard deviation, based on participants' results.

For paraquat in material $A$ the uncertainty of the consensus value did comply with the criterion $\mathrm{u} \leq 0.3 \sigma_{\mathrm{p}}$ and was therefore considered as negligible. The uncertainty of the consensus value (u) in material $A$ exceeded $0.3 \sigma_{p}$ for diquat and in material $B$ for paraquat and diquat, and therefore, the uncertainty of the consensus value was taken into account in the evaluation of the z-scores. For material $A$, one of the reported results for diquat was a questionable result (PT9312), and one of the reported results for paraquat was questionable (PT9370). For material B, three of the reported results 
for diquat were questionable (PT9367, PT9378, PT9380) and one result was unsatisfactory (PT9312) and for paraquat two of the reported results were questionable (PT9376, PT9380) and one result was unsatisfactory (PT9312).

Table 7 Parameters of diquat and paraquat in material A.

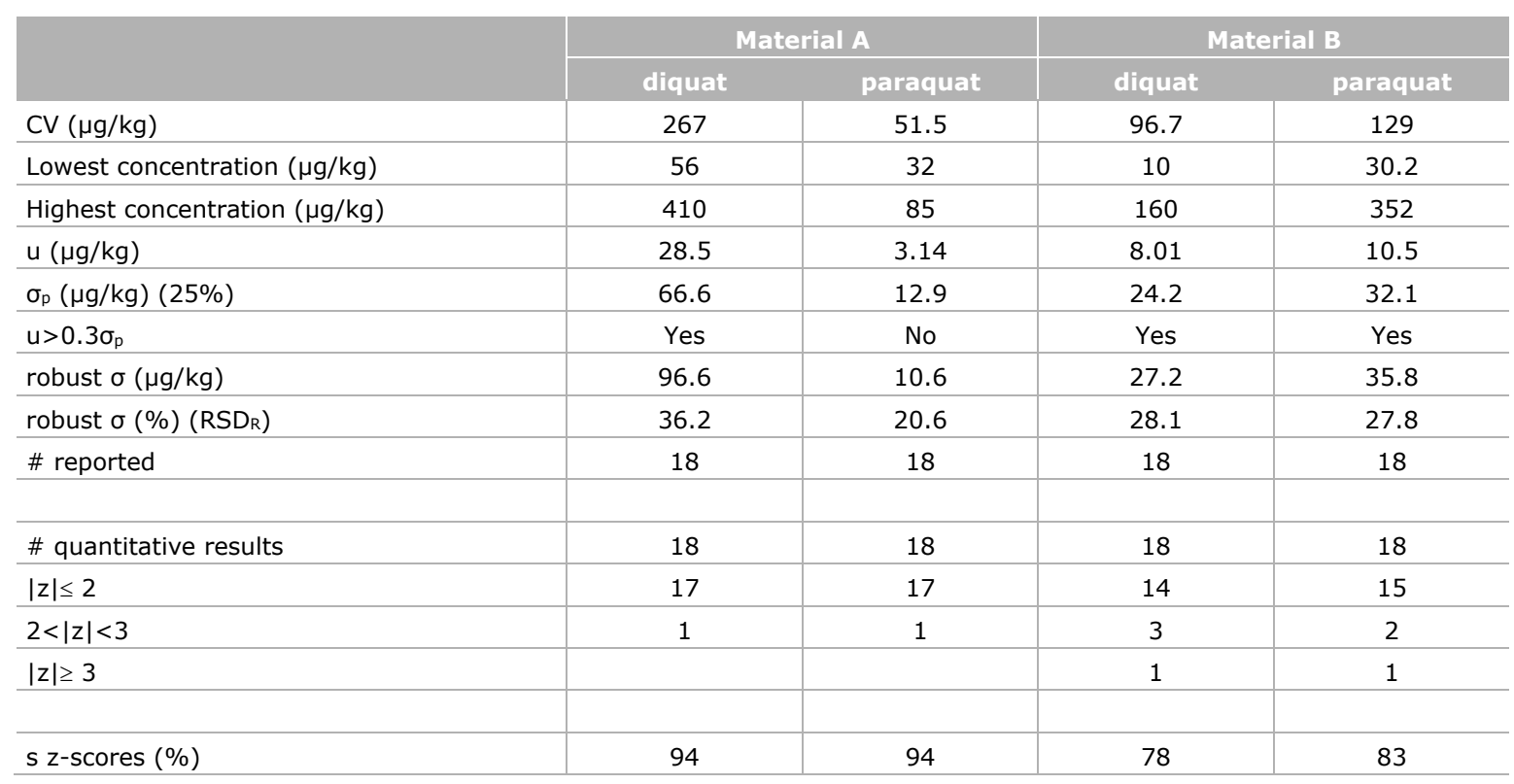

The consensus values for diquat and paraquat in material A were respectively 267 and $51.5 \mu \mathrm{g} / \mathrm{kg}$ and in material B respectively 96.7 and $129 \mu \mathrm{g} / \mathrm{kg}$.

The robust relative standard deviation $\left(R \mathrm{RD}_{R}\right)$ was calculated according to ISO13528:2015 [4] for informative purposes only. In this study it was used as a good estimation of the interlaboratory variability. The $\mathrm{RSD}_{\mathrm{R}}$ values for each pesticide in both materials are shown in Annex 6 and in Table 7.

For material $A$, the robust standard deviations $\left(R S D_{R}\right)$ of the reported results for paraquat $(21 \%)$ in $A$ was below the target standard deviation (25\%) and for diquat $(36 \%)$ the RSD $_{R}$ exceeded the target standard deviation. For material $\mathrm{B}$, the $\mathrm{RSD}_{\mathrm{R}}$ values were close to the target standard deviation for both pesticides $(28 \%)$.

For material A, 94\% of the results were rated with satisfactory $z$-scores $(|z| \leq 2), 6 \%$ of the results felt into the questionable range with $2<|z|<3$. For material $\mathrm{B} 81 \%$ of the results were rated with satisfactory $z$-scores $(|z| \leq 2), 14 \%$ of the results felt into the questionable range with $2<|z|<3$ and $6 \%$ of the results felt into the unsatisfactory range with $|z| \geq 3$.

In Annex 7 an overview of the overall performance of each participant in this PT is summarised. For the two materials combined, a maximum of 4 satisfactory z-scores could be obtained, and ' 4 out of 4' therefore reflects an optimal performance in terms of scope and capability for quantitative determination.

All 18 participants analysed the materials for both pesticides. Out of these 18 participants, 12 participants achieved optimal performance for both materials by detecting both pesticides with correct quantification, the absence of false positive and/or false negative results, and reporting all results within the set deadline. 


\section{Discussion and conclusions}

Eighteen participants participated in the proficiency test on diquat and paraquat in the feed matrix soybean meal.

Two materials were sent to the participants. The pesticides were homogeneously distributed in the materials. An overview of each participant's performance is shown in Annex 7 and a summary of the results is presented in Table 6.

Out of 18 participants 12 showed optimal performance by detecting both pesticides with a correct quantification, the absence of false positive or false negative results and reporting within the deadline. Six participants reported questionable or unsatisfactory z-scores. A total of seven questionable z-scores and two unsatisfactory z-score were reported.

For the pesticides in material $A, 94 \%$ of the reported results were satisfactory. In material $B, 78 \%$ of the reported results were satisfactory for diquat and $83 \%$ for paraquat.

The robust relative standard deviation $\left(R S D_{R}\right)$ was close to the target standard deviation, with the exception of diquat in material A (36\%), indicating that the $25 \%$ target standard deviation is reasonably reflecting the current interlaboratory variability for diquat and paraquat in soybean meal.

Overall, for diquat and paraquat in both materials combined, $87.5 \%$ of the results were rated with satisfactory $z$-scores $(|z| \leq 2), 9.7 \%$ of the results fell into the questionable range with $2<|z|<3$ and $2.8 \%$ of the results fell into the unsatisfactory range with $|z| \geq 3$.

Based on the results of this proficiency test it was concluded that:

- The satisfactory results for diquat and paraquat varied from $78-94 \%$ in this proficiency test. No explanation can be given for the lower satisfactory results for diquat (78\%) and paraquat (83\%) in material $B$ as opposed to material A.

- The interlaboratory reproducibility (RSDR) ranged from $21-36 \%$.

- Overall result of this PT: $67 \%$ of the participants showed optimal performance. 


\section{References}

1 ISO/IEC 17025:2017 (E). 2017. General Requirements for the Competence of Calibration and Testing Laboratories.

2 ISO/IEC 17043:2010. 2010. Conformity assessment - General requirements for proficiency testing.

3 SOPA0989 - De bereiding van referentiematerialen en referentiemonsters - WFSR.

4 ISO 13528:2015, IDT. 2015. Statistical methods for use in proficiency testing by inter-laboratory comparison, 1st edition.

5 Thompson M. 2000. Recent trends in inter-laboratory precision at $\mu \mathrm{g} / \mathrm{kg}$ and sub- $\mu \mathrm{g} / \mathrm{kg}$ concentrations in relation to fitness for purpose criteria in proficiency testing. Analyst. 125: 385-386.

6 Thompson M, Ellison SL, Wood R. 2006. The International Harmonized Protocol for the Proficiency Testing of Analytical Chemistry Laboratories. Pure Appl. Chem. 78(1):145-196.

7 Analytical Methods Committee. 1989. Robust statistics - How not to reject outliers Part 1. Basic concepts. Analyst 114:1693-1697.

8 Analytical Methods Committee. 1989. Robust statistics - How not to reject outliers Part 2. Inter-laboratory trials. Analyst. 114:1699-1702.

9 Regulation (EC) No 396/2005 of 23 February 2005 on maximum residue levels of pesticides in or on food and feed of plant and animal origin and amending Council 91/414/EEC.

10 Target standard deviation for proficiency assessment $\left(\sigma_{P}\right)$ of $25 \%$ used in proficiency tests on pesticides organised by the pesticides EURLs[10]. https://www.eurl-pesticides.eu/library/docs/allcrl/EUPT-General_Protocol_V9_2020.pdf 


\section{Annex 1 Codification of the samples}

\begin{tabular}{|c|c|c|}
\hline Participants code & $\begin{array}{l}\text { Last three digits of codes } \\
\text { Material A* }\end{array}$ & $\begin{array}{l}\text { Last three digits of codes } \\
\qquad \text { Material B* }\end{array}$ \\
\hline PT9312 & 316 & 419 \\
\hline PT9367 & 205 & 837 \\
\hline PT9368 & 431 & 995 \\
\hline PT9369 & 561 & 352 \\
\hline PT9370 & 181 & 959 \\
\hline PT9371 & 321 & 400 \\
\hline PT9372 & 552 & 916 \\
\hline РT9373 & 468 & 516 \\
\hline РT9374 & 987 & 515 \\
\hline РТ9375 & 847 & 104 \\
\hline PT9376 & 269 & 463 \\
\hline PT9377 & 703 & 733 \\
\hline PT9378 & 224 & 169 \\
\hline РT9379 & 902 & 220 \\
\hline РT9380 & 386 & 724 \\
\hline PT9381 & 426 & 583 \\
\hline РT9382 & 575 & 137 \\
\hline PT9383 & 344 & 110 \\
\hline РT9384 & 793 & 929 \\
\hline
\end{tabular}

* All sample codes start with 2020/pesticides/soybean/ 


\section{Annex 2 Instruction letter}

WAGENINGEN

UNIVERSTYY \& RESEARCH

January 20, 2020

sinat

Instruction profidency test polar pesticides diquat and paraquat in foed matix

soybean meal.

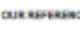

2000730/WFS

Poswinosenss

6700 AE WAGENINGEN

Dear Madam/Sir,

The Netherlind:

Thank you very much for your interest in the proficiency test for the analysis of the polar pesticides diquat and paraquat in the feed matrix soybean meal. Hereby I send you a parcel containing two randomly coded samples. Each sample consists of approximately 50 grams of test material.

Please fill out the accompanying acknowledgement of receipt form and return it immediately upon receipt of the samples, preferably by e-mail (pt.wfsr@wur.nl)

vasues neosios

Wageningen Campus

Bulling 123

Akcermaslsbos 2

6708 WB WAGENINGEN

wwow.mur.en

cocousen:

Instructions:

After arrival the samples should be stored at $+4{ }^{\circ} \mathrm{C}$.

Before analysis, homogenize them according to your laboratory's procedure.

Treat the test material as if it was a sample for routine analysis.

Report one result and not an average of multiple measurements for each sample.

Report all results in $\boldsymbol{\mu g} / \mathbf{k g}$ for the product as received (i.e. no correction for moisture content is needed). When a pesticide is not within your scope, please report 'nt' (not tested) in the web application. Do not use the option 'detected' from the web application. When a pesticide is 'not detected' or the result is below your LOQ, report the result as $\angle L O Q$-value and specify the value (e.g. $<20$ $\mu \mathrm{g} / \mathrm{kg}$ ).

Please use the web application for entering your results (https://crlwebshop, wur. nl/apex/f?p=307:LOGIN). Information about the use of this web application was sent to you earlier by e-mail.

The deadline for submitting test-results for this test is $\mathbf{2}^{\text {th }}$ of March 2020.

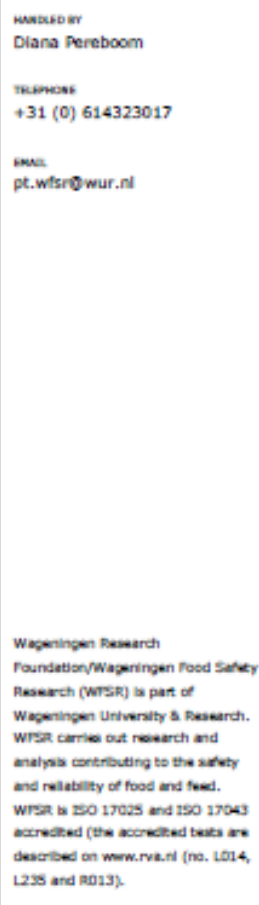




\begin{tabular}{|c|c|c|}
\hline Dars & - & Your username is: \\
\hline January 20,2020 & - & Your password is: \\
\hline 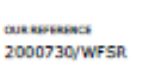 & - & Your lab code to enter this proficiency test is: \\
\hline $\operatorname{mos}_{2 \mathrm{of}} 2$ & - & $\begin{array}{l}\text { Please inform us about your applied method and detection technique } \\
\text { (via the web application). }\end{array}$ \\
\hline
\end{tabular}

With kind regards,

D. Pereloom

Diana Pereboom

Proficiency tests

pt.wfsr@wur.nl 


\section{Annex 3 Statistical evaluation of homogeneity data}

\begin{tabular}{|c|c|c|}
\hline \multirow[b]{2}{*}{ Sample No. } & \multicolumn{2}{|c|}{ Diquat in material $\mathbf{A}(\mu \mathrm{g} / \mathrm{kg})$} \\
\hline & Replicate 1 & Replicate 2 \\
\hline Hom/A001 & 265 & 265 \\
\hline Hom/A002 & 252 & 311 \\
\hline $\mathrm{Hom} / \mathrm{A003}$ & 263 & 288 \\
\hline Hom/A004 & 315 & 260 \\
\hline Hom/A005 & 289 & 288 \\
\hline Hom/A006 & 252 & 307 \\
\hline Hom/A007 & 310 & 259 \\
\hline Hom/A008 & 285 & 317 \\
\hline Hom/A009 & 303 & 276 \\
\hline Hom/A010 & 290 & 249 \\
\hline Grand mean & \multicolumn{2}{|c|}{282} \\
\hline \multicolumn{3}{|l|}{ Cochran's test } \\
\hline $\mathrm{C}$ & \multicolumn{2}{|c|}{0.219} \\
\hline $\mathrm{C}_{\text {crit }}$ & \multicolumn{2}{|c|}{0.602} \\
\hline $\mathrm{C}<\mathrm{C}_{\text {crit }}$ ? & \multicolumn{2}{|c|}{ NO OUTLIERS } \\
\hline Target $\mathrm{S}=\sigma_{\mathrm{P}}$ & \multicolumn{2}{|c|}{70.5} \\
\hline$s_{x}$ & \multicolumn{2}{|c|}{10.4} \\
\hline $\mathrm{S}_{\mathrm{w}}$ & \multicolumn{2}{|c|}{28.9} \\
\hline $\mathrm{s}_{\mathrm{s}}$ & \multicolumn{2}{|c|}{0.000} \\
\hline Critical $=0.3 \sigma_{p}$ & \multicolumn{2}{|c|}{21.2} \\
\hline $\mathrm{S}_{\mathrm{s}}<$ critical? & \multicolumn{2}{|c|}{ ACCEPTED } \\
\hline $\mathrm{s}_{\mathrm{w}}<0.5 \sigma_{\mathrm{p}} ?$ & \multicolumn{2}{|c|}{ ACCEPTED } \\
\hline
\end{tabular}

$\mathrm{s}_{\mathrm{x}}=$ Standard deviation of the sample averages.

$\mathrm{S}_{\mathrm{w}}=$ Within-sample standard deviation.

$\mathrm{s}_{\mathrm{s}}=$ Between-sample standard deviation.

\begin{tabular}{|c|c|c|}
\hline \multirow[b]{2}{*}{ Sample No. } & \multicolumn{2}{|c|}{ Paraquat in material A $(\mu \mathrm{g} / \mathrm{kg})$} \\
\hline & Replicate 1 & Replicate 2 \\
\hline Hom/A001 & 54.6 & 54.5 \\
\hline Hom/A002 & 50.3 & 54.1 \\
\hline Hom/A003 & 52.2 & 57.8 \\
\hline Hom/A004 & 56.8 & 52.9 \\
\hline Hom/A005 & 54.2 & 53.4 \\
\hline Hom/A006 & 49.0 & 49.3 \\
\hline Hom/A007 & 54.3 & 54.3 \\
\hline Hom/A008 & 52.6 & 52.7 \\
\hline Hom/A009 & 52.9 & 53.3 \\
\hline Hom/A010 & 58.2 & 53.2 \\
\hline Grand mean & \multicolumn{2}{|c|}{53.5} \\
\hline \multicolumn{3}{|l|}{ Cochran's test } \\
\hline $\mathrm{C}$ & \multicolumn{2}{|c|}{0.369} \\
\hline$C_{\text {crit }}$ & \multicolumn{2}{|c|}{0.602} \\
\hline $\mathrm{C}<\mathrm{C}_{\text {crit }}$ ? & \multicolumn{2}{|c|}{ NO OUTLIERS } \\
\hline Target $\mathrm{s}=\sigma_{\mathrm{P}}$ & \multicolumn{2}{|c|}{13.4} \\
\hline $\mathrm{s}_{\mathrm{x}}$ & \multicolumn{2}{|c|}{1.89} \\
\hline $\mathrm{S}_{w}$ & \multicolumn{2}{|c|}{2.09} \\
\hline $\mathrm{s}_{\mathrm{s}}$ & \multicolumn{2}{|c|}{1.17} \\
\hline Critical $=0.3 \sigma_{p}$ & \multicolumn{2}{|c|}{4.02} \\
\hline $\mathrm{S}_{\mathrm{s}}<$ critical? & \multicolumn{2}{|c|}{ ACCEPTED } \\
\hline $\mathrm{s}_{\mathrm{w}}<0.5 \sigma_{\mathrm{p}} ?$ & \multicolumn{2}{|c|}{ ACCEPTED } \\
\hline
\end{tabular}




\begin{tabular}{|c|c|c|}
\hline \multirow[b]{2}{*}{ Sample No. } & \multicolumn{2}{|c|}{ Diquat in material B $(\mu \mathrm{g} / \mathrm{kg})$} \\
\hline & Replicate 1 & Replicate 2 \\
\hline Hom/A001 & 99.4 & 93.3 \\
\hline Hom/A002 & 112 & 97.4 \\
\hline Hom/A003 & 96.0 & 90.8 \\
\hline Hom/A004 & 104 & 99.9 \\
\hline Hom/A005 & 99.1 & 102 \\
\hline Hom/A006 & 88.3 & 96.5 \\
\hline Hom/A007 & 89.6 & 102 \\
\hline Hom/A008 & 100 & 107 \\
\hline Hom/A009 & 92.9 & 105 \\
\hline Hom/A010 & 102 & 92.0 \\
\hline Grand mean & \multicolumn{2}{|c|}{98.4} \\
\hline \multicolumn{3}{|l|}{ Cochran's test } \\
\hline $\mathrm{C}$ & \multicolumn{2}{|c|}{0.256} \\
\hline $\mathrm{C}_{\text {crit }}$ & \multicolumn{2}{|c|}{0.602} \\
\hline $\mathrm{C}<\mathrm{C}_{\text {crit }}$ ? & \multicolumn{2}{|c|}{ NO OUTLIERS } \\
\hline Target $\mathrm{s}=\sigma_{\mathrm{p}}$ & \multicolumn{2}{|c|}{24.6} \\
\hline $\mathrm{s}_{\mathrm{x}}$ & \multicolumn{2}{|c|}{4.10} \\
\hline $\mathrm{S}_{\mathrm{w}}$ & \multicolumn{2}{|c|}{6.33} \\
\hline $\mathrm{S}_{\mathrm{s}}$ & \multicolumn{2}{|c|}{0.000} \\
\hline Critical $=0.3 \sigma_{p}$ & \multicolumn{2}{|c|}{7.38} \\
\hline $\mathrm{s}_{\mathrm{s}}<$ critical? & \multicolumn{2}{|c|}{ ACCEPTED } \\
\hline $\mathrm{S}_{\mathrm{w}}<0.5 \sigma_{\mathrm{p}} ?$ & \multicolumn{2}{|c|}{ ACCEPTED } \\
\hline
\end{tabular}

\begin{tabular}{|c|c|c|}
\hline \multirow[b]{2}{*}{ Sample No. } & \multicolumn{2}{|c|}{ Paraquat in material B $(\mu \mathrm{g} / \mathrm{kg})$} \\
\hline & Replicate 1 & Replicate 2 \\
\hline Hom/A001 & 152 & 140 \\
\hline Hom/A002 & 150 & 135 \\
\hline Hom/A003 & 153 & 155 \\
\hline Hom/A004 & 144 & 138 \\
\hline Hom/A005 & 146 & 166 \\
\hline Hom/A006 & 142 & 138 \\
\hline Hom/A007 & 170 & 136 \\
\hline Hom/A008 & 136 & 145 \\
\hline Hom/A009 & 146 & 144 \\
\hline Hom/A010 & 147 & 143 \\
\hline Grand mean & \multicolumn{2}{|c|}{98.4} \\
\hline \multicolumn{3}{|l|}{ Cochran's test } \\
\hline $\mathrm{C}$ & \multicolumn{2}{|c|}{0.550} \\
\hline $\mathrm{C}_{\text {crit }}$ & \multicolumn{2}{|c|}{0.602} \\
\hline $\mathrm{C}<\mathrm{C}_{\text {crit }}$ ? & \multicolumn{2}{|c|}{ NO OUTLIERS } \\
\hline Target $\mathrm{s}=\sigma_{\mathrm{p}}$ & \multicolumn{2}{|c|}{36.6} \\
\hline$S_{x}$ & \multicolumn{2}{|c|}{5.92} \\
\hline $\mathrm{S}_{\mathrm{w}}$ & \multicolumn{2}{|c|}{10.2} \\
\hline $\mathrm{s}_{\mathrm{s}}$ & \multicolumn{2}{|c|}{0.000} \\
\hline Critical $=0.3 \sigma_{p}$ & \multicolumn{2}{|c|}{11.0} \\
\hline $\mathrm{s}_{\mathrm{s}}<$ critical? & \multicolumn{2}{|c|}{ ACCEPTED } \\
\hline $\mathrm{s}_{\mathrm{w}}<0.5 \sigma_{\mathrm{p}} ?$ & \multicolumn{2}{|c|}{ ACCEPTED } \\
\hline
\end{tabular}




\section{Annex 4 Statistical evaluation of stability data}

Statistical evaluation for diquat in material A.

\begin{tabular}{|c|c|c|}
\hline Storage temperature & $<-18^{\circ} \mathrm{C}$ & $<4^{\circ} \mathrm{C}$ \\
\hline Time (days) & 0 & 89 \\
\hline \multirow[t]{4}{*}{ Calculated amounts $(\mu \mathrm{g} / \mathrm{kg})$} & $*$ & 311 \\
\hline & 298 & 292 \\
\hline & 287 & 322 \\
\hline & 302 & 340 \\
\hline Average amount $(\mu \mathrm{g} / \mathrm{kg})$ & 310 & 314 \\
\hline $\mathrm{n}$ & 5 & 6 \\
\hline st. dev $(\mu \mathrm{g} / \mathrm{kg})$ & 20.6 & 16.7 \\
\hline Difference & & -4.31 \\
\hline
\end{tabular}

*Outlier according to grubbs'test

Statistical evaluation for paraquat in material A.

\begin{tabular}{ccc} 
Storage temperature & $<-18{ }^{\circ} \mathrm{C}$ & $<{ }^{\circ} \mathrm{C}$ \\
Time (days) & 0 & 59.1 \\
\hline Calculated amounts $(\mu \mathrm{g} / \mathrm{kg})$ & $*$ & 56.0 \\
& 58.6 & 60.4 \\
& 52.1 & 52.3 \\
& 58.5 & 59.5 \\
\hline Average amount $(\mu \mathrm{g} / \mathrm{kg})$ & 55.7 & 57.3 \\
$\mathrm{n}$ & 59.0 & 6 \\
st. dev $(\mu \mathrm{g} / \mathrm{kg})$ & 56.8 & 2.91 \\
Difference & 5 & -0.51 \\
$0.3 * \sigma_{p}$ & 2.92 & 4.26 \\
\hline
\end{tabular}

*Outlier according to grubbs'test 


\section{Statistical evaluation for diquat in material B.}

\begin{tabular}{|c|c|c|}
\hline Storage temperature & $<-18^{\circ} \mathrm{C}$ & $<4^{\circ} \mathrm{C}$ \\
\hline Time (days) & 0 & 89 \\
\hline \multirow[t]{4}{*}{ Calculated amounts $(\mu \mathrm{g} / \mathrm{kg})$} & 93.6 & 78.0 \\
\hline & 102 & 85.2 \\
\hline & 84.0 & 92.4 \\
\hline & 97.6 & 114.5 \\
\hline Average amount $(\mu \mathrm{g} / \mathrm{kg})$ & 95.9 & 96.1 \\
\hline $\mathrm{n}$ & 6 & 6 \\
\hline st. dev $(\mu \mathrm{g} / \mathrm{kg})$ & 6.45 & 13.9 \\
\hline Difference & & -0.22 \\
\hline
\end{tabular}

Statistical evaluation for paraquat in material B.

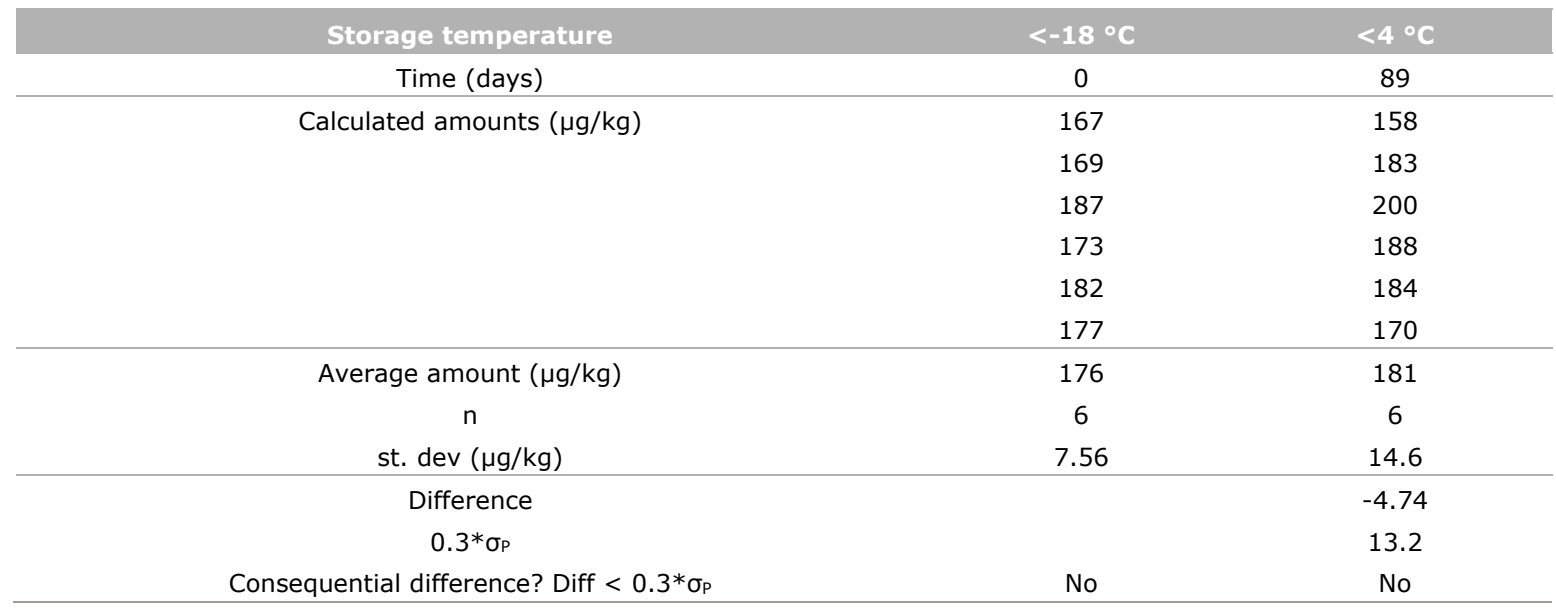




\section{Annex 5 Overview of the applied methods}

\begin{tabular}{|c|c|c|c|c|c|c|c|}
\hline \multirow[t]{2}{*}{ Lab } & \multirow[t]{2}{*}{ Sample purification } & \multirow[t]{2}{*}{ Internal standard } & \multicolumn{2}{|c|}{ LOD $\mu g / k g$} & \multicolumn{2}{|c|}{ LOQ $\mu g / k g$} & \multirow{2}{*}{$\begin{array}{l}\text { Detectiol } \\
\text { method }\end{array}$} \\
\hline & & & Diquat & Paraquat & Diquat & Paraquat & \\
\hline PT9312 & Water/formic acid extraction plus cleanup with Bond Elut $\mathrm{C} 18$ & Diquat-D4, Paraquat-D6 & 3 & 6 & 10 & 20 & LC-MS/MS \\
\hline PT9367 & Acid hydrolysis and clean-up & Yes & 5 & 5 & 10 & 10 & LC-MS/MS \\
\hline PT9368 & $2.5 \mathrm{~g}$ sample $+25 \mathrm{ml} \mathrm{MeOH} / \mathrm{HCl} 0.1 \mathrm{M}$ after centrifugation fill a vial & Paraquat-D6 & 5 & 5 & 10 & 10 & LC-MS/MS \\
\hline PT9369 & Extraction with an acidified mixture of methanol and water & Diquat-D4, Paraquat-D8 & & & 10 & 10 & LC-MS/MS \\
\hline PT9370 & $\begin{array}{l}1: 1 \text { mixture of methanol }+ \text { aqueous } \mathrm{HCl} 0.1 \mathrm{M} \text {, extraction in shaking water bath at } 80^{\circ} \mathrm{C} \text { for } \\
15 \text { minutes, freeze- out and cold centrifugation. }\end{array}$ & Diquat-D4, Paraquat-D8 & 5 & 5 & 10 & 10 & LC-MS/MS \\
\hline \multicolumn{8}{|c|}{ 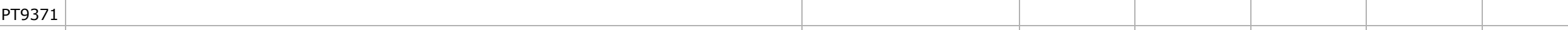 } \\
\hline PT9372 & $0.5 \mathrm{M} \mathrm{HCL}$ in $40 \% \mathrm{MeOH}$ & & 10 & 10 & 10 & 10 & LC-MS/MS \\
\hline PT9373 & & & 10 & 10 & & & LC-MS/MS \\
\hline PT9374 & & & & & & & LC-MS/MS \\
\hline PT9375 & $\begin{array}{l}\text { Quick Polar Pesticides-Method PO V10.1; 5.2.3.Extraction B) Procedure for Paraquat and } \\
\text { Diquat }\end{array}$ & Diquat-D4, Paraquat-D6 & & & 20 & 20 & LC-MS/MS \\
\hline PT9376 & $\begin{array}{l}\text { weigh } 5 \text { gram, add internal standard, add } 20 \mathrm{ml} \text { water, vortex, add } 20 \mathrm{ml} \text { extraction solvent } \\
(50 \% \text { methanol, } 0.15 \% \mathrm{HCl}) \text {, vortex, place in water bath ( } 80 \text { degrees) for } 20 \text { minutes, cool } \\
\text { down, centrifuge @ } 3600 \mathrm{rpm} \text { for } 5 \text { minutes, place in filter vial }\end{array}$ & Diquat-D6, Paraquat-D8 & & & 10 & 20 & LC-MS/MS \\
\hline PT9377 & Weigh $1 \mathrm{~g}$ of the sample into a tube $(50 \mathrm{~mL})$. Add $10 \mathrm{~mL}$ of $\mathrm{MeOH}+3 \%$ formic acid & Paraquat-D6 & & & 10 & 10 & LC-MS/MS \\
\hline PT9378 & $\begin{array}{l}\text { Diquat: } 5 \mathrm{~g} \text { of matrix, } 10 \mathrm{~mL} \text { of Methanol, heat until } 80^{\circ} \mathrm{C} \text {, cool down, centrifuge and filter. } \\
\text { Paraquat: } 5 \mathrm{~g} \text { of matrix, } 5 \mathrm{~g} \text { of water, } 10 \mathrm{~mL} \text { of Methanol } 3 \% \text { formic acid, heat until } 80^{\circ} \mathrm{C} \text {, cool } \\
\text { down, centrifugue and filter. }\end{array}$ & & & & 10 & 10 & LC-MS/MS \\
\hline PT9380 & $\begin{array}{l}2 \mathrm{~g} \text { sample }+(9 \mathrm{~mL} \text { water }+1 \mathrm{~mL} \text { EDTA } 10 \% \text { solution })+10 \mathrm{~mL}(\mathrm{MeOH} / \mathrm{HCl} 0.1 \mathrm{M} 1: 1 \text { solution })+ \\
80^{\circ} \mathrm{C} 15 \text { minutes }\end{array}$ & Not used & & & & & LC-MS/MS \\
\hline PT9381 & $\begin{array}{l}\text { In accordance with Quick polar Pesticides method (QuPPe) and QuPPe-AO with following } \\
\text { exceptions: extraction with H2O:MeOH:Formic acid = 60:39:1 instead of 49.5:49.5:1. After } \\
\text { heating, extraction with DCM for better separation }\end{array}$ & Diquat-D4, Paraquat-D6 & 17 & 19 & 20 & 20 & LC-MS/MS \\
\hline PT9382 & Acidified extraction and SPE. & Isotopic labeled standards & 1.7 & 2 & 5.6 & 6.8 & LC-MS/MS \\
\hline PT9383 & & & & & 0.01 & 0.01 & \\
\hline PT9384 & Quick Polar pesticides method & & & & & & LC-MS/MS \\
\hline
\end{tabular}




\section{Annex 6 Results material A and B}

\begin{tabular}{|c|c|c|c|c|c|c|c|c|}
\hline \multirow[b]{2}{*}{$\begin{array}{l}\text { Lab } \\
\text { code }\end{array}$} & \multicolumn{2}{|c|}{$\begin{array}{c}\text { Material A } \\
\text { diquat } \\
\text { CV: } 267 \mu \mathrm{g} / \mathrm{kg} \\
\text { u: } 28.5 \mu \mathrm{g} / \mathrm{kg} \\
\sigma_{\mathrm{p}}: 66.6 \mu \mathrm{g} / \mathrm{kg} \\
\text { robust } \sigma: 96.6 \mu \mathrm{gg} / \mathrm{kg} \\
(36 \%)\end{array}$} & \multicolumn{2}{|c|}{$\begin{array}{c}\text { Material A } \\
\text { paraquat } \\
\text { CV: } 51.5 \mu \mathrm{g} / \mathrm{kg} \\
\text { u: } 3.14 \mu \mathrm{g} / \mathrm{kg} \\
\sigma_{\mathrm{p}:} 12.9 \mu \mathrm{g} / \mathrm{kg} \\
\text { robust o: } 10.6 \mu \mathrm{g} / \mathrm{kg} \\
(21 \%)\end{array}$} & \multicolumn{2}{|c|}{$\begin{array}{c}\text { Material B } \\
\text { diquat } \\
\text { CV: } 96.7 \mu g / k g \\
\text { u: } 8.01 \mu \mathrm{g} / \mathrm{kg} \\
\sigma_{\mathrm{p}}: 24.2 \mu \mathrm{gg} / \mathrm{kg} \\
\text { robust } 0: 27.2 \mu \mathrm{g} / \mathrm{kg} \\
(28 \%)\end{array}$} & \multicolumn{2}{|c|}{$\begin{array}{c}\text { Material B } \\
\text { paraquat } \\
\text { CV: } 129 \mu \mathrm{g} / \mathrm{kg} \\
\text { u: } 10.5 \mu \mathrm{g} / \mathrm{kg} \\
\sigma_{\mathrm{p}}: 32.1 \mu \mathrm{g} / \mathrm{kg} \\
\text { robust } 0: 35.8 \mu \mathrm{g} / \mathrm{kg} \\
(28 \%)\end{array}$} \\
\hline & $\begin{array}{l}\text { Result } \\
\text { ( } \mu \mathrm{g} / \mathrm{kg})\end{array}$ & $z^{\prime}$ a-score & $\begin{array}{l}\text { Result } \\
(\mu \mathrm{g} / \mathrm{kg})\end{array}$ & za-score & $\begin{array}{c}\text { Result } \\
(\mu g / k g)\end{array}$ & $\mathbf{z}^{\prime} \mathrm{a}$-score & $\begin{array}{c}\text { Result } \\
(\mu \mathrm{g} / \mathrm{kg})\end{array}$ & $\mathrm{z}^{\prime} \mathrm{a}$-score \\
\hline PT9312 & 56 & -2.91 & 54 & 0.20 & 10 & -3.40 & 352 & 6.61 \\
\hline PT9367 & 410 & 1.98 & 43 & -0.66 & 160 & 2.49 & 118 & -0.31 \\
\hline PT9368 & 370 & 1.43 & 57 & 0.43 & 105 & 0.33 & 127 & -0.05 \\
\hline PT9369 & 206.6 & -0.83 & 42.2 & -0.72 & 90.8 & -0.23 & 119.4 & -0.27 \\
\hline PT9370 & 230 & -0.50 & 85 & 2.61 & 90 & -0.26 & 110 & -0.55 \\
\hline PT9371 & 318 & 0.71 & 43 & -0.66 & 110 & 0.52 & 145 & 0.49 \\
\hline PT9372 & 344 & 1.07 & 53 & 0.12 & 121 & 0.96 & 131 & 0.07 \\
\hline PT9373 & 263 & -0.05 & 62 & 0.82 & 91 & -0.22 & 173 & 1.32 \\
\hline PT9374 & 290 & 0.32 & 48 & -0.27 & 130 & 1.31 & 120 & -0.25 \\
\hline PT9375 & 311 & 0.61 & 51 & -0.04 & 110 & 0.52 & 149 & 0.61 \\
\hline PT9376 & 293 & 0.37 & 64 & 0.97 & 125 & 1.11 & 213 & 2.50 \\
\hline PT9377 & 187 & -1.10 & 32 & -1.51 & 62 & -1.36 & 79 & -1.46 \\
\hline PT9378 & 130 & -1.88 & 56 & 0.35 & 45 & -2.03 & 100 & -0.84 \\
\hline PT9380 & 143.5 & -1.70 & 60.3 & 0.69 & 38.7 & -2.28 & 30.2 & -2.91 \\
\hline PT9381 & 370 & 1.43 & 47 & -0.35 & 98 & 0.05 & 150 & 0.64 \\
\hline PT9382 & 292.7 & 0.36 & 59.1 & 0.59 & 108.2 & 0.45 & 153.1 & 0.73 \\
\hline PT9383 & 307 & 0.56 & 48 & -0.27 & 101 & 0.17 & 128 & -0.02 \\
\hline PT9384 & 184 & -1.14 & 35.3 & -1.26 & 66.2 & -1.20 & 62.4 & -1.96 \\
\hline
\end{tabular}

$\mathrm{C}=$ consensus value (robust mean)

$\mathrm{u}=$ uncertainty of consensus value

$\sigma_{\mathrm{p}}=$ target standard deviation for proficiency

robust $\sigma=$ robust (relative) standard deviation based on participants' results 


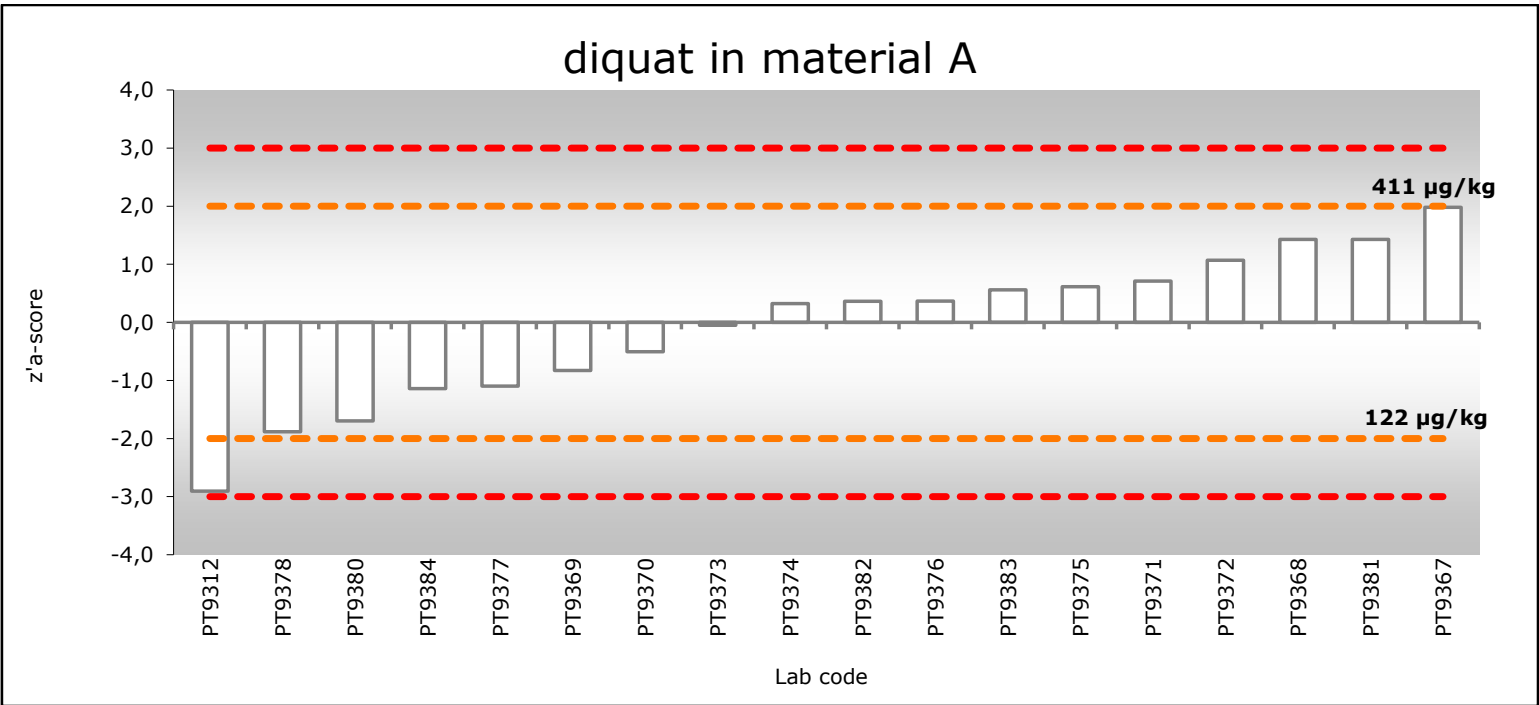

Figure a Graphical representation of the $z_{a}^{\prime}$-scores for diquat in material $A$. The $X \pm 2 \sigma_{P}$ lines (dotted) are calculated according to equation II in §3.4.

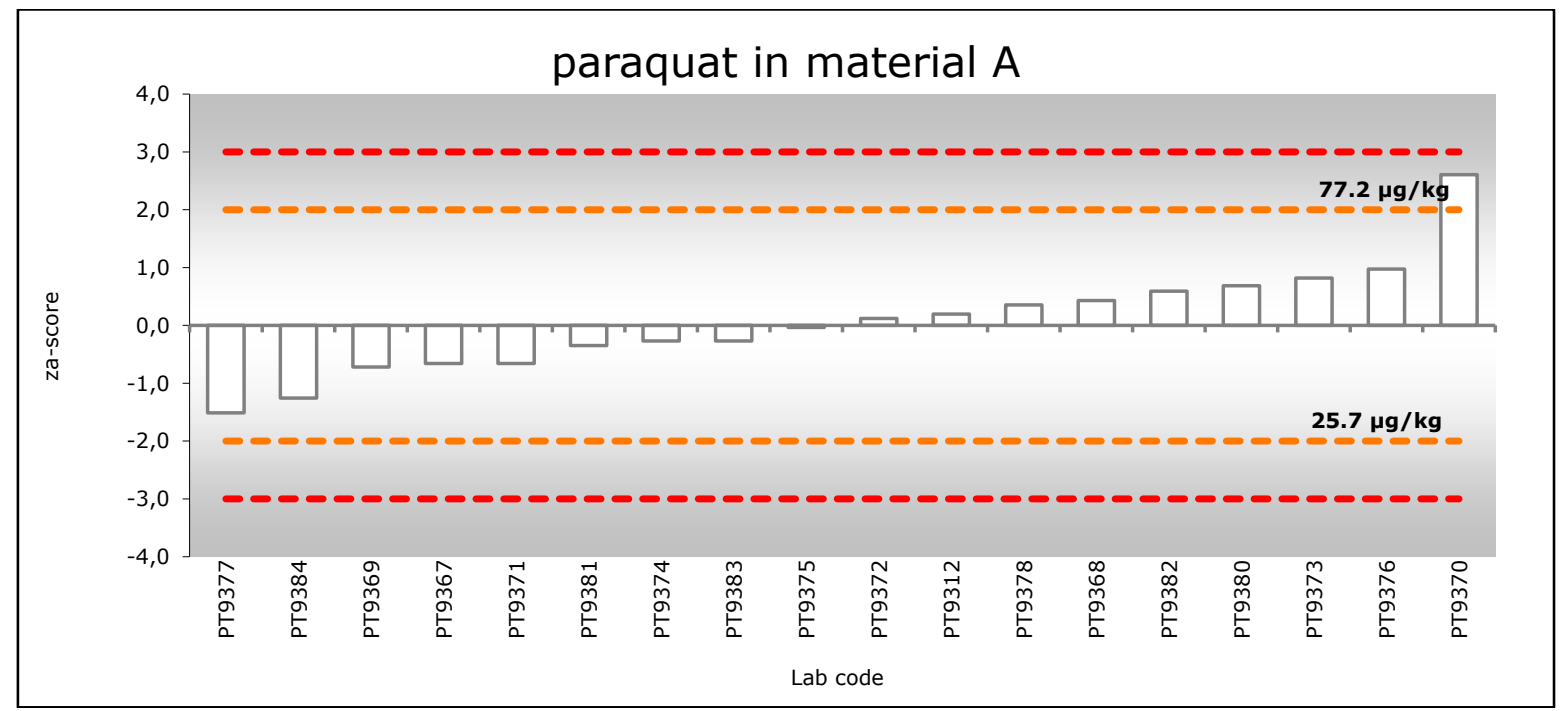

Figure $\boldsymbol{b} \quad$ Graphical representation of the $z_{a}$-scores for paraquat in material $A$. The $X \pm 2 \sigma_{P}$ lines (dotted) are calculated according to equation I in §3.4. 


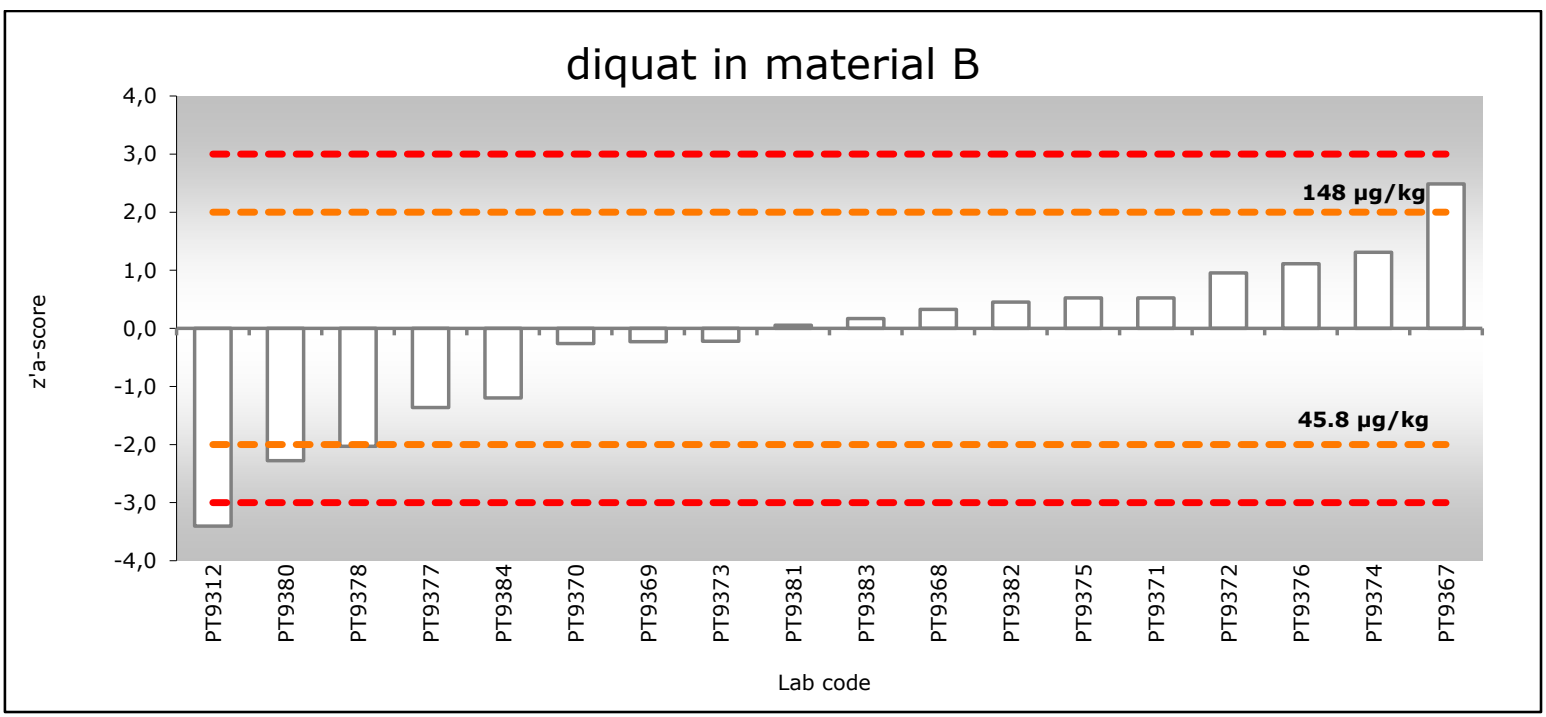

Figure $\mathbf{c} \quad$ Graphical representation of the $z_{a}^{\prime}$-scores for diquat in material $B$. The $X \pm 2 \sigma_{P}$ lines (dotted) are calculated according to equation II in §3.4.

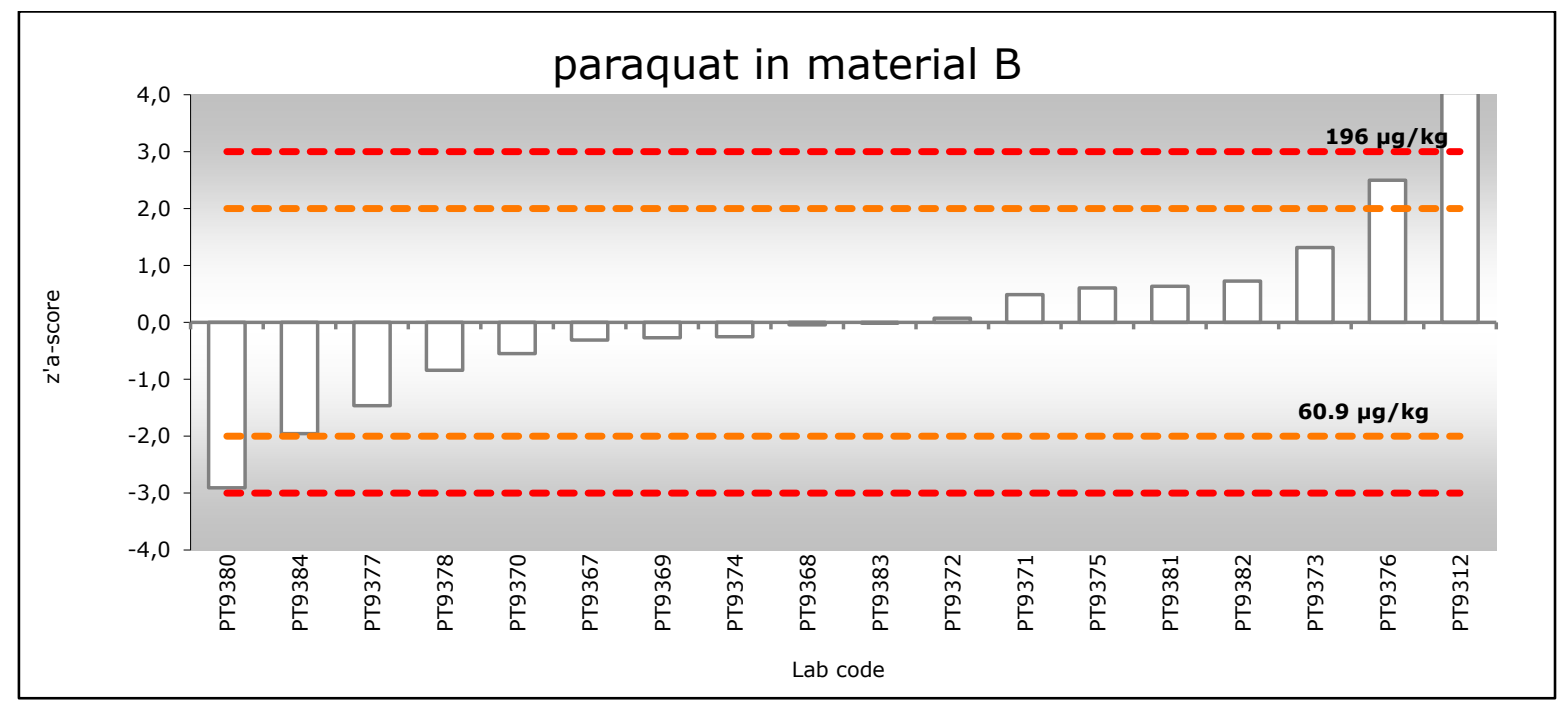

Figure d Graphical representation of the $z_{a}^{\prime}$-scores for paraquat in material $B$. The $X \pm 2 \sigma_{P}$ lines (dotted) are calculated according to equation II in §3.4. 


\section{Annex 7 Overview performance per laboratory}

\begin{tabular}{|c|c|}
\hline Laboratory code & Satisfactory performance \\
\hline PT9312 & 1 of 4 \\
\hline PT9367 & 3 of 4 \\
\hline PT9368 & 4 of 4 , optimal performance \\
\hline PT9369 & 4 of 4 , optimal performance \\
\hline PT9370 & 3 of 4 \\
\hline PT9371 & 4 of 4 , optimal performance \\
\hline PT9372 & 4 of 4 , optimal performance \\
\hline PT9373 & 4 of 4 , optimal performance \\
\hline PT9374 & 4 of 4 , optimal performance \\
\hline PT9375 & 4 of 4 , optimal performance \\
\hline PT9376 & 3 of 4 \\
\hline PT9377 & 4 of 4 , optimal performance \\
\hline PT9378 & 3 of 4 \\
\hline PT9380 & 2 of 4 \\
\hline PT9381 & 4 of 4 , optimal performance \\
\hline PT9382 & 4 of 4 , optimal performance \\
\hline PT9383 & 4 of 4 , optimal performance \\
\hline PT9384 & 4 of 4 , optimal performance \\
\hline
\end{tabular}


Wageningen Food Safety Research

P.O. Box 230

6700 AE Wageningen

The Netherlands

T +31 (0)317480256

www.wur.eu/food-safety-research

WFSR report 2020.013
The mission of Wageningen University \& Research is "To explore the potential of nature to improve the quality of life". Under the banner Wageningen University \& Research, Wageningen University and the specialised research institutes of the Wageningen Research Foundation have joined forces in contributing to finding solutions to important questions in the domain of healthy food and living environment. With its roughly 30 branches, 5,000 employees and 12,000 students, Wageningen University \& Research is one of the leading organisations in its domain. The unique Wageningen approach lies in its integrated approach to issues and the collaboration between different disciplines. 



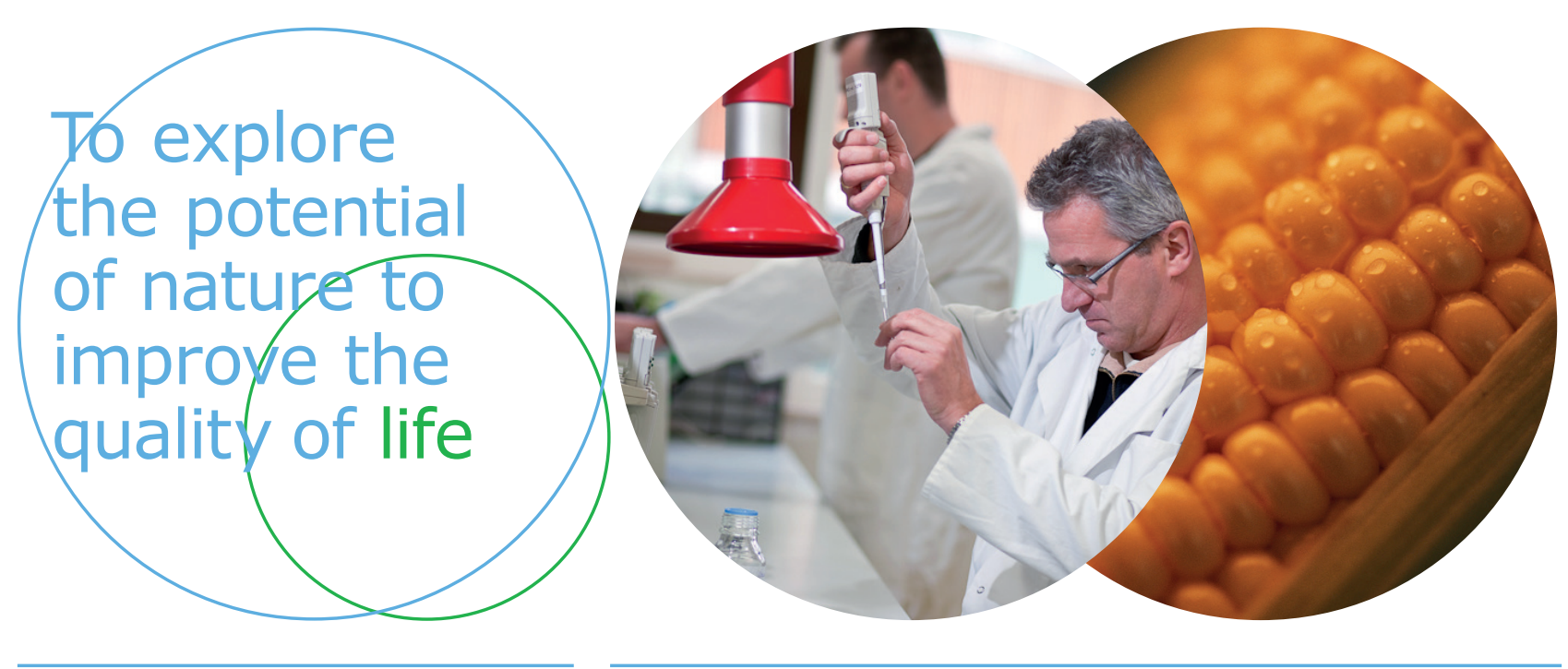

Wageningen Food Safety Research P.O. Box 230

6700 AE Wageningen

The Netherlands

T +31 (0)317480256

www.wur.eu/food-safety-research

WFSR report 2020.013
The mission of Wageningen University \& Research is "To explore the potential of nature to improve the quality of life". Under the banner Wageningen University $\&$ Research, Wageningen University and the specialised research institutes of the Wageningen Research Foundation have joined forces in contributing to inding solutions to important questions in the domain of healthy food and living environment. With its roughly 30 branches, 5,000 employees and 12,000 students, Wageningen University \& Research is one of the leading organisations in its domain. The unique Wageningen approach lies in its integrated approach to issues and the collaboration between different disciplines. 